Supporting information for

\title{
Blowing DNA bubbles
}

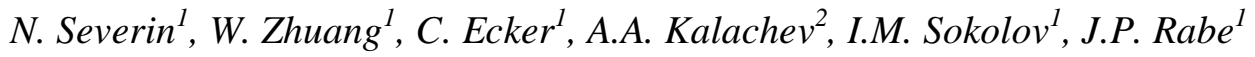 \\ ${ }^{1}$ Department of Physics, Humboldt University Berlin, Newtonstr. 15, D-12489 Berlin, \\ Germany \\ ${ }^{2}$ Plasmachem GmbH, Rudower Chaussee 29, D-12489 Berlin, Germany
}

We observe blowing effect also with polymer molecules deposited on graphite surface coated with an ultrathin liquid film only, without amphiphiles. Vector DNA molecules (MoBiTec GmbH, pUC19, 2686 BP) were applied to graphite surface by drying a droplet of DNA dilute solution in milli-Q water $\left(10^{-3} \mathrm{~g} / \mathrm{l}\right)$. SFM imaging of dry surface revealed aggregates of DNA molecules with occasional small molecular loops protruding out of the aggregates (Fig 1 a). SFM imaging shortly after spin coating of hexane reveals that the loops formed by the DNA molecules blow, which one can see by the characteristic contrast between inside and outside of the loops and by the blown shape of the loops (Fig. 1 b). The contrast between inside and outside of the loop disappears, after breakage of one of the DNA loops by the SFM tip (Fig $1 \mathrm{c}, \mathrm{d})$. 

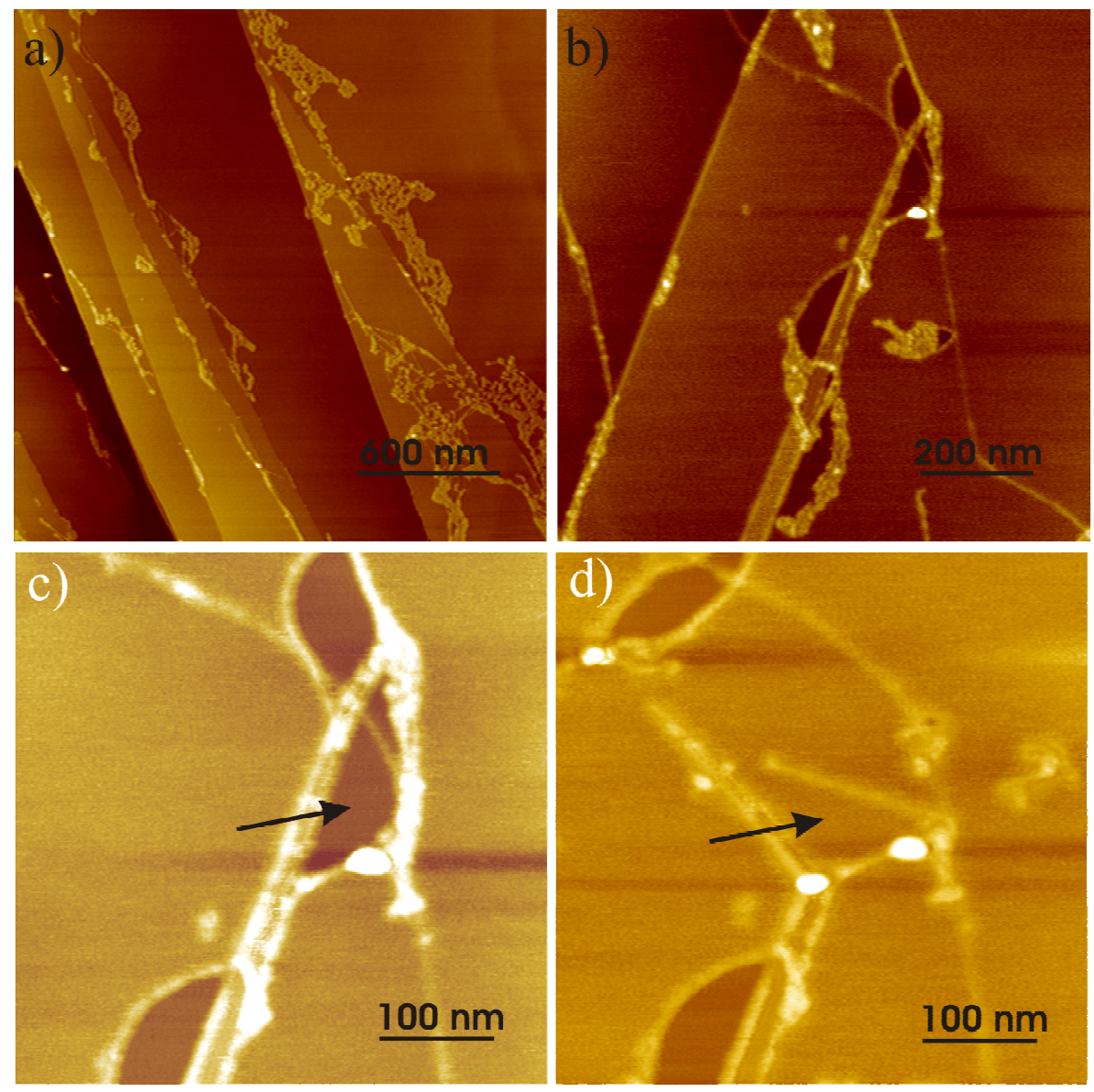

Fig. 1: a) Aggregates of vector DNA molecules on dry graphite surface. b) Blowing of DNA loops after application of hexane. c) Zoom in from b). d) The contrast between inside and outside of the loop disappears after breaking one of the DNA molecules with the SFM tip. The loop which was broken is indicated with arrows. 